Nova Southeastern University

$8-1-2018$

\title{
Antipredatory Escape Behaviors of Two Benthic Ctenophores in South Florida
}

Peter W. Glynn

University of Miami

Brian Coffman

Florida International University

Jeongran Vanderwoude

University of Miami

Nicolas Martinez

Florida International University

Joshua H. Dominguez

University of Miami

See next page for additional authors

Find out more information about Nova Southeastern University and the Halmos College of Natural Sciences and Oceanography.

Follow this and additional works at: https://nsuworks.nova.edu/occ_facarticles

Part of the Marine Biology Commons, and the Oceanography and Atmospheric Sciences and Meteorology Commons

\section{NSUWorks Citation}

Peter W. Glynn, Brian Coffman, Jeongran Vanderwoude, Nicolas Martinez, Joshua H. Dominguez, Julie M. Gross, and Dorothy-Ellen A. Renegar. 2018. Antipredatory Escape Behaviors of Two Benthic Ctenophores in South Florida .Ecology : 1 -11.

https://nsuworks.nova.edu/occ_facarticles/950. 
Authors

Julie M. Gross

University of Miami

Dorothy-Ellen A. Renegar

Nova Southeastern University, drenegar@nova.edu 
Article type : The Scientific Naturalist

\section{Antipredatory escape behaviors of two benthic ctenophores in South Florida}

Peter W. Glynn ${ }^{1,5}$, Brian Coffman², Jeongran Vanderwoude ${ }^{3}$, Nicolas Martinez ${ }^{3}$, Joshua H. Dominguez $^{3}$, Julie M. Gross ${ }^{3}$, D. Abigail Renegar ${ }^{4}$

${ }^{1}$ Department of Marine Biology and Ecology, Rosenstiel School of Marine and Atmospheric Science, University of Miami, 4600 Rickenbacker Causeway, Miami, Florida 33149, USA

${ }^{2}$ SE Environmental Research Center \& Department of Biological Sciences, Florida International University, Miami, Florida 33199, USA

${ }^{3}$ Undergraduate Marine and Atmospheric Science Program, Rosenstiel School of Marine and Atmospheric Science, University of Miami, 1365 Memorial Drive, 210 Ungar Building, Coral Gables, Florida 33146, USA

${ }^{4}$ Department of Marine and Environmental Science, Halmos College of Natural Sciences and Oceanography, Nova Southeastern University, 8000 North Ocean Drive, Dania Beach, Florida 33004, USA

${ }^{5}$ Corrsponding Author. E-mail: pglynn@ rsmas.miami.edu

Manuscript Type and Running Head: The Scientific Naturalist

Manuscript received 17 April 2018; revised 1 June 2018; 10 July 2018.

This article has been accepted for publication and undergone full peer review but has not been through the copyediting, typesetting, pagination and proofreading process, which may lead to differences between this version and the Version of Record. Please cite this article as doi: 10.1002/ecy.02497

This article is protected by copyright. All rights reserved. 
Corresponding Editor: John Pastor

Benthic ctenophores, members of the family Coeloplanidae (Order Platyctenida, Phylum Ctenophora) are more widespread and abundant in tropical and subtropical marine environments than formerly recognized. Coeloplanid ctenophores are members of the most speciose family of benthic ctenophores, with 33 recognized species of Coeloplana and one species of the genus Vallicula (Mills 1998). The majority of coeloplanids are ectosymbionts of algae and diverse benthic invertebrates (Matsumoto 1999, Alamaru et al. 2015). Hundreds to thousands of individuals can occupy preferred habitats in $<1 \mathrm{~m}^{2}$ of substrate patches. Galt (1998) noted Vallicula multiformis inhabiting algae in Hawaii at population densities as high as 10,000 individuals $\mathrm{m}^{-2}$. Also, in South Florida Glynn et al. (2017) observed 100s of individuals of $V$. multiformis inhabiting macroalgae, and 1,000 to 1,500 individuals of Coeloplana waltoni on octocoral stems.

Like many of their pelagic counterparts, benthic ctenophores are efficient predators, employing a pair of extensible tentacles with numerous short tentilla (side-branches) armed with colloblasts (sticky cells) that assist in prey capture. When fishing, the tentacles can extend to at least 5-10 times the body length, capturing mesozooplankton, both holoplankton and meroplankton. These planktonic components often include fish eggs and larvae (Glynn et al. 2018), both of which play a crucial role in population counts of many species. Studies have generally focused on the predatory behavior of benthic ctenophores with the functional role of tentacles involved in the capture of zooplankton (Rankin 1956, Emson and Whitfield 1991, Eeckhaut et al. 1997). However, recent observations have shown that tentacles may serve an 
alternative purpose. Here we offer behavioral and photographic evidence that coeloplanid tentacles may also function defensively in protection against predators. Here we describe the defensive behaviors of Vallicula multiformis Rankin 1956 and Coeloplana waltoni Glynn, Bayer \& Renegar 2014. Vallicula multiformis occurs in shallow (0.25-2.0 m depth), sheltered biofouling communities, commonly ranges $2-8 \mathrm{~mm}$ in body length, and often assumes the color of its biotic host. Coeloplana waltoni occurs at 2-10 m depth on octocorals in exposed coastal habitats, is 1-2 mm in body length, translucent, and notably cryptic. Both ctenophore species inhabit species-rich communities with numerous potential predators and competitors. Two types of ctenophore defensive behaviors are herein described, the extension of compact tentacle tangles by V. multiformis (Fig. 1a, b), and shelter-seeking behavior beside and within octocoral host calyces and polyps by $C$. waltoni (Fig. 1c, d).

All behaviors reported here were observed in captive animals in southeast Florida over a few days to several weeks' duration on multiple occasions from 2014 to 2018. Ctenophore host algae and octocorals served as natural substrates for $V$. multiformis and $C$. waltoni, respectively. Observations were made visually with the naked eye and microscopically at 8 to $35 \mathrm{X}$ magnification. Agitation or predator simulation was effected by pricking ctenophores, dislodging them from a resting position by forceful water jets, and probing with a cheliped of a known crab predator [Portunus sayi (Gibbes 1850)]. Additionally, naturally occurring live predators of $V$.

multiformis, the sea anemone Exaiptasia pallida (Agassiz in Verrill, 1864), and of C. waltoni, the gastropod mollusk Cyphoma gibbosum Linnaeus 1758 and the pygmy angelfish Centropyge argi Woods \& Kanazawa 1951, were offered ctenophore prey (see Glynn et al. 2018).

This article is protected by copyright. All rights reserved. 
Individuals of $V$. multiformis remained motionless under low light and low flow to still water conditions. In feeding trials, tentacle extension occurred in a matter of minutes in flowing water with zooplankton. Tentacles were greatly extended, several times the ctenophore's body length, with tentilla regularly spaced and deployed along their lengths. Upon agitation - for example by performing a simulated predator attack - ctenophores quickly, within a few seconds, extended both tentacles as a dense tangle on each side of the body (Fig. 1a, b). Accompanying tentacle extrusion, the ctenophores typically flattened their bodies (oral side) against the substrate and remained motionless. Upon repeated stimulation they would begin to move; mean escape locomotion was $0.13 \mathrm{~mm} \mathrm{~s}^{-1}(\mathrm{n}=6$ individuals). Some fleeing ctenophores retracted the tentacle tangles, while others left them extended.

When feeding, the tentacle extension behavior of individuals of $C$. waltoni was similar to that of $V$. multiformis. However, individuals of $C$. waltoni would typically move to the outer rims of octocoral calices to better position themselves for tentacle extension in the water column. Upon stimulation, $C$. waltoni would quickly retract its tentacles and move away from the point of contact. Mean escape locomotion was $0.067 \mathrm{~mm} \mathrm{~s}^{-1}(\mathrm{n}=5$ individuals), about one-half the fleeing rate of $V$. multiformis. Fleeing individuals would typically approach an octocoral polyp and attempt to enter the polyp's calyx (a protective cup). This escape behavior occurred most often in smaller individuals ( $1 \mathrm{~mm}$ in length). The ctenophores were usually repulsed by the occupying polyps that expanded and physically blocked entry. As a result, ctenophore individuals usually settled with partial entry or around the bases of calyces where they were still 
well camouflaged and virtually invisible (Fig. 1c, d). The time to seek refuge usually ranged between 30 to 60 seconds.

Horizontal exposure in Petri dishes of nearly equal-sized $(<1 \mathrm{~cm}$ greatest body length) individuals of both $V$. multiformis and the anemone E. pallida, resulted in the sea anemone immediately grasping the ctenophore with a tentacle and pulling it toward its mouth. In response, the ctenophore quickly ejected tentacle tangles that ensnared several of the anemone's tentacles. Thus began a back and forth "tug-of-war" that lasted from 2 to 3 minutes, with both individuals engaged in rapid tentacle contraction and relaxation. The anemone was the first to disengage from the encounter, with tentacle relaxation, thus allowing the ctenophore to escape. During vertical feeding trials, when ctenophores were introduced onto the oral disc from above

(Glynn et al. 2018), anemones were usually successful in subduing and ingesting the ctenophores, suggesting that the angle of contact (horizontally from the benthos or vertically from the plankton) could be a critical factor in prey capture or escape.

Active encounters between individuals of $C$. waltoni on their octocoral hosts with the non-visual mollusk grazer and the visual fish predator generally involved ctenophore body contractions and tentacle retraction. Continuing mollusk grazing, and pursuit by the angelfish resulted in ctenophore fleeing behavior and seeking shelter. Grazing gastropods invariably consumed sheltering ctenophores, but the capture success of ctenophores by fish predators was greatly reduced.

This article is protected by copyright. All rights reserved. 
There are few behavioral observations of ctenophores involved in escape responses

(Mackie et al. 1992, Matsumoto and Harbison 1993, Mackie 1995). All pelagic species studied showed increasing swimming responses to stimulation, effected by ciliary activity and muscular contractions of the body. In Mackie's (1995) review of the defensive strategies of pelagic cnidarians and ctenophores, he emphasized the importance of reducing accidental contact and damage caused by associated zooplankters instead of damage from predators. Of the three major defensive categories reviewed by Mackie - involution, intimidation (visual displays), and escape -C. waltoni often demonstrated a type of involution, i.e. slight crumpling when stimulated, and both ctenophore species performed different styles of escape behavior. In regards to intimidation, no bioluminescent responses were observed in the benthic coeloplanids; however, larger individuals of $C$. waltoni assumed a pinkish color in the warmer months (June-October) that made them slightly more visible. V. multiformis typically remained motionless and extruded both tentacles as compact, twisted masses. C. waltoni would usually flee, taking refuge adjacent to octocoral calyces and polyps. In addition, mimicry - adoption of host coloration by $V$. multiformis, and host color and texture by $C$. waltoni (by virtue of translucency) - likely plays a role in reducing injuries and losses from visual predators.

In conclusion, the various defensive behaviors described here likely contribute to the notably high abundances of benthic ctenophores in the species-rich octocoral and biofouling communities in subtropical South Florida. A chief focus of future studies should verify the occurrence of these laboratory observations under natural field conditions. Further, attention should be directed toward identifying the predators of benthic ctenophores and their influence on ctenophore population control and structure.

This article is protected by copyright. All rights reserved. 


\section{Acknowledgments}

Thanks are due the personnel of the Parks, Recreation and Open Spaces Department, namely Robert McQueeny, Marjorie Suarez and Chantal Victor, Miami-Dade County, Florida for allowing access and collections at the Crandon Park Marina. Liza Merly and Larry Brand kindly loaned laboratory supplies. We also thank Sam Maddingly and Tom Hughes, South Florida Beach Divers Club, for help with ctenophore collections. Claudia E. Mills offered helpful suggestions that improved this note.

\section{Literature Cited}

Alamaru, A., E. Brokovich, and Y. Loya. 2015. Four new species and three new records of benthic ctenophores (Family: Coeloplanidae) from the Red Sea. Marine Biodiversity 46:261-279.

\footnotetext{
Alamaru, A., B. W. Hoeksema, S. E. T. van der Meij, and D. Huchon. 2017. Molecular diversity of benthic ctenophores (Coeloplanidae). Scientific Reports, Nature 7:6365

DOI:10.1038/s41598017-06505-4.
}

This article is protected by copyright. All rights reserved. 
Eeckhaut, I., P. Flammang, and C. Lo Bue. 1997. Functional morphology of the tentacles and tentilla of Coeloplana bannworthi (Ctenophora, Platyctenida), an ectosymbiont of Diadema setosum (Echinodermata, Echinoidea). Zoomorphology 117:165-174.

Emson, R. H. and P. J. Whitfield. 1991. Behavioral and ultrastructural studies on the sedentary platyctenean ctenophore Vallicula multiformis. Hydrobiologia 216/217:27-33.

Galt, C. P. 1998. Natural history of the benthic ctenophore Vallicula multiformis in Kaneohe Bay, Hawaii. (Abstr.) American Zoologist 38(5):181a.

Glynn, P. W., F. M. Bayer, and D. Abigail Renegar. 2014. Coeloplana waltoni, a new species of minute benthic ctenophore (Ctenophora: Platyctenida) from south Florida. Proceedings of the Biological Society of Washington 127(2):423-436.

Glynn, P. W., B. Coffman, M. P. C. Fuller, S. G. Moorhead, M. K. Williams, K. D. Primov, T. N. Fortson, R. N. Barrales, and P. J. Glynn. 2017. Benthic ctenophores (Platyctenida: Coeloplanidae) in south Florida: environmental conditions, habitats, abundances, and behaviors.

Invertebrate Biology 1-15. https://doi.org/10.1111/ivb.12189.

This article is protected by copyright. All rights reserved. 
Glynn, P. W., B. Coffman, K. D. Primov, S. G. Moorhead, J. Vanderwoude, R. N. Barrales, M. K. Williams, and R. P. Roemer. 2018. Benthic ctenophores (Platyctenida: Coeloplanidae) in south Florida: predator-prey interactions. Invertebrate Biology 1-18. doi:10.1111/ivb.12212.

Mackie, G. O. 1995. Defensive strategies in planktonic coelenterates. Mar. Fresh. Behav.

Physiol. 26: 119-129.

Mackie, G. O., Mills, C. E., and C. L. Singla. 1992. Giant axons and escape swimming in Euplokamis dunlapae (Ctenophora: Cydippida). Biological Bulletin 182: 248-256.

Matsumoto, G. I. 1999. Coeloplana thompsoni sp. nov., a new benthic ctenophore (Ctenophora:

Platyctenida: Coeloplanidae) from Western Australia. In: The Sea Grass Flora and Fauna of

Rottnest Island, Western Australia. D. I. Walker and F. E. Wells (Eds.), pp. 385-393, Proceedings of the $9^{\text {th }}$ International Marine Biological Workshop, held at Rottnest Island, Western Australia, January 1996. Western Australian Museum, Perth, Western Australia.

Matsumoto, G. I. and G. R. Harbison. 1993. In situ observations of foraging, feeding and escape behavior in three orders of oceanic ctenophores: Lobata, Cestida, and Beroida. Marine Biology 117: 279-287.

This article is protected by copyright. All rights reserved. 
Mills, C. E. 1998. Phylum Ctenophora: list of all valid species names. Available online at http://faculty.washington.edu/cemills/Ctenolist.html. Published by the author, web page established March 1998, last updated 12 June 2017.

Rankin, J. J. 1956. The structure and biology of Vallicula multiformis, gen. et sp. nov., a platyctenid ctenophore. Journal of the Linnaean Society of London, Zoology 43:55-71.

Fig. 1 Photomicrographs of two individuals of Vallicula multiformis (a, b) motionless with fully extended tentacle tangles, $\sim 5 \mathrm{~mm}$ body lengths; an individual of Coeloplana waltoni on 208 octocoral host Eunicea tourneforti moving rapidly in escape response past a calyx (c), and 209 attempting to enter a calyx (d), $1.5 \mathrm{~mm}$ body length.

This article is protected by copyright. All rights reserved. 

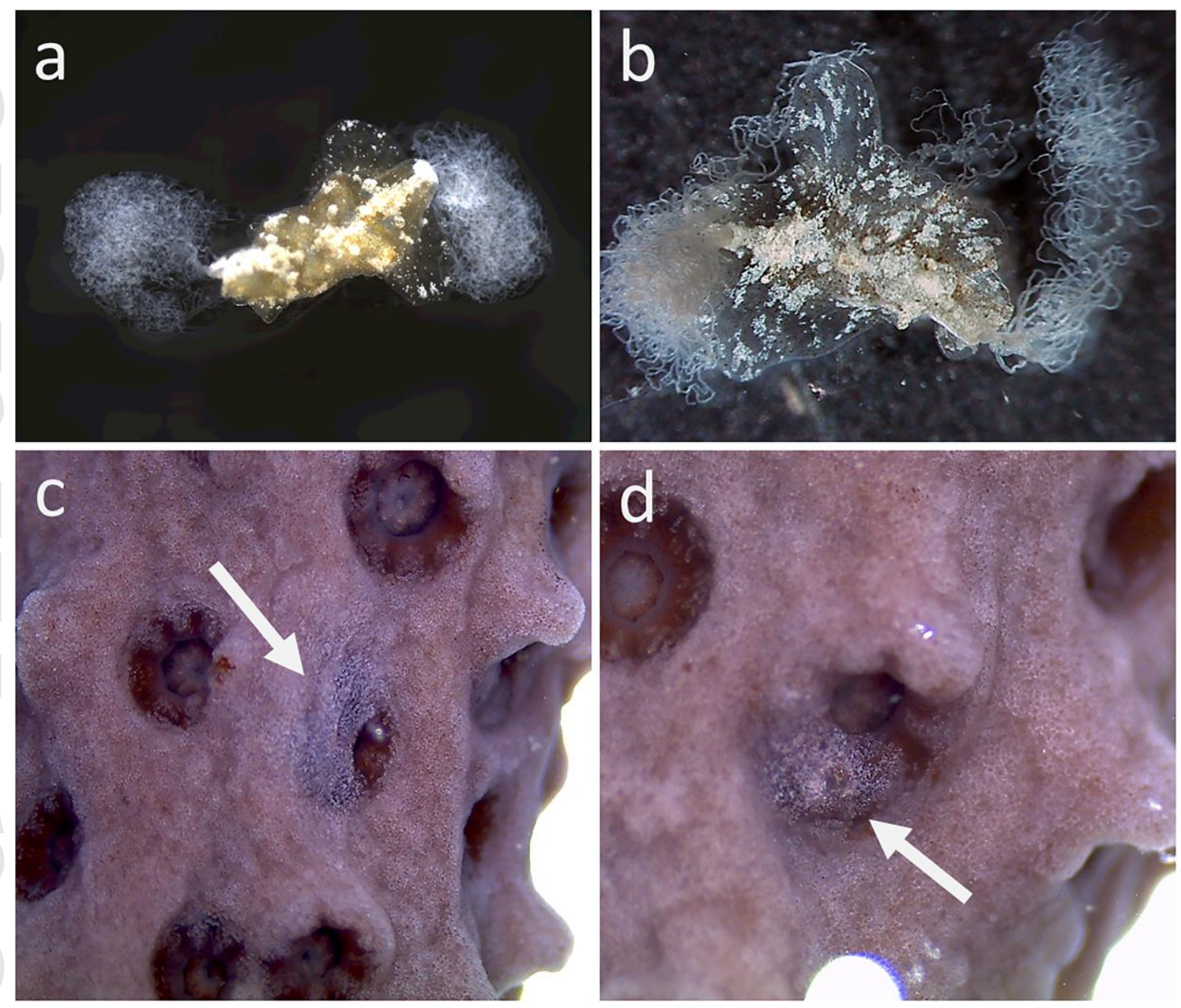

This article is protected by copyright. All rights reserved. 